DOI 10.37882/2500-3682.2021.06.11

\title{
ИНТЕРПРЕТАЦИЯ ВИЗАНТИЙСКОЙ МУЗЫКАЛЬНОЙ ТРАДИЦИИ В ХРИСТИАНСКОЙ КУЛЬТУРЕ СИРИИ
}

\section{INTERPRETATION OF BYZANTINE MUSICAL TRADITION IN THE CHRISTIAN CULTURE OF SYRIA}

\section{Maksoud Marilyn}

Summary: The article examines the manifestation and rooting of the Byzantine musical tradition in the Orthodox Christian culture of the Syrian people. The origin of the Syrian Orthodox church music culture can be traced back to the dawn of Christianity. The first religious Christian compositions were based on folklore tradition. And also their basis was the ritual pagan chants that preceded them, modified for the needs of the new doctrine. Music in the Byzantine Christian Church is primarily about prayer. Therefore, no musical instruments were used in it. The role of the patriarchs of the Syrian Orthodox Church and contemporary composers in strengthening and popularizing the Byzantine musical tradition is noted.

Keywords: Syrian Arab Republic, Syrian Orthodox tradition, Byzantine musical tradition, Christian culture of Syria, Byzantine Christian church, Syrian culture, traditions, psalms, Arab Caliphate, Ottoman Empire.

\author{
Максуд Марлен \\ Аспирант, Санкт-Петербургский государственный \\ университет, Санкт-Петербург \\ marilyn.maksoud@gmail.com
}

Аннотация: В статье рассмотрено проявление и укоренение византийской музыкальной традиции в православной христианской культуре сирийского народа. Зарождение сирийской православной церковной музыкальной культуры можно проследить еще на заре христианства. Первые религиозные христианские композиции опирались на фольклорную традицию. А также их основой стали предшествовавшие им обрядовые языческие песнопения, видоизмененные для нужд нового вероучения. Музыка в византийской христианской церкви - это, в первую очередь, молитва. Поэтому в ней не использовались музыкальные инструменты. Отмечена роль патриархов сирийской православной церкви и современных композиторов в укреплении и популяризации византийской музыкальной традиции.

Ключевые слова: Сирийская православная традиция, византийская музыкальная традиция, христианская культура Сирии, византийская христианская церковь, сирийская культура, псалмы, Арабский халифат, Османская империя.

«Столетия сирийская культура сосуществовала с другими культурами в таких государствах, как Римская империя, Византийская империя, Арабский халифат и Османская империя» [11, с. 84]. До сегодняшнего дня в сирийской культуре «сохранились традиции многих других культур, они не исчезли, а продолжают существовать» [4, с. 328]. Тем не менее, сирийцы смогли сохранить собственную культурную идентичность. Хотя, с другой стороны, «благодаря постоянному диалогу с разными культурами, сирийская культура обрела уникальность и стала примером существования единого культурного пространства» [5, с. 90].

Выдающийся зарубежный ученый Джеймс Фрэзер (1854-1941) произнёс следующие слова: «Каждая вера выражается при помощи соответствующей музыки... Расстояние, которое отделяет дикие оргии Кибелы от торжественного ритуала католической церкви, количественно выражается в пропасти, которая отделяет нестройный гул кимвалов и бубнов от величественной гармонии Палестрины и Генделя. Сквозь различную музыку проглядывают здесь различия духовного порядка» [20, с. 106].

Очевидно, что этими словами Джеймс Фрэзер стремился показать значимость религиозной музыки в отражении духовной жизни народа, а также, духовное превосходство христианства над язычеством. «Сопо- 
ставление же единых критериев - абсурд, особенно если дело касается столь утонченной и индивидуальной сферы творчества, как создание музыкального произведения» [21, с. 109]. Такими словами оценил данное сравнение российский музыковед, исследователь античной и византийской музыки Е.В. Герцман.

Принято считать, что сирийский народ - носитель сирийского языка, происходит от древней Ассирийской империи. На это обстоятельство указывает то, что «многие сирийские ортодоксальные гимны дошли до нас из песенных стихов древних ассирийцев» [19]. Когда мы говорим о сирийской культуре начала XXI столетия, мы имеем в виду не жителей какой-либо определенной страны, а арамеоязычных жителей Востока.

Распространено также мнение, что сирийская музыкальная культура произошла от церковной музыки религиозного характера и её возникновение напрямую связано с распространением христианства среди населения арамеоязычных стран. Однако данное мнение ошибочно, поскольку «сирийская музыка - это тип музыкальные мелодии, принятый арамеями задолго до обращения ими в христианство и вхождения в Церковь» $[2$, c. 62].

Известный сирийский композитор Нури Искандар, утверждал, что «сирийская церковная музыка является продолжением древней языческой музыкальной традиции Сирии и Месопотамии» [10]. Отметим, что сирийская музыка - это в основном лирические произведения, а не инструментальная музыка. Именно композитор Нури Искандар принес новые традиции и сочинял музыкальные произведения для оркестров с инструментами (виолончель, уд, бузук и другие музыкальные инструменты). С тех пор современная, но непопулярная музыка, приобрела новую форму.

Но возникают два пороса: какова связь между сирийско-антиохийской музыкой и византийской музыкой, которая, в первую очередь, также является Антиохийской? И что является мостом, связующим звеном между этими двумя видами музыки? В качестве ответа подчеркнем, что у них есть общие черты:

1- восемь мелодий;

2- наличие коротких мелодий определенного ритма.

Разница заключается лишь в том, что византийская музыка увеличила мелодический спектр композиции, более похожий на восточный мувашахат в Алеппо. Византийская музыка - это очень благоговейная музыка, соответствующая империи и величию (музыка дворцов императоров и великих соборов). Она заставляет чувствовать строгость. Отличительной чертой сирийской музыки является фольклор, народная музыка, музыка христиан, простых людей, которые поют для того, чтобы наполнить свое сердце светом Святого Духа.

Не смотря на огромное значение, которое уделяется духовной музыке сегодня, в раннехристианской церкви музыка была запрещена при проведении обрядов. Она считалась инструментом для пробуждения инстинктов. Подобная негативная оценка музыки была связана во многом с неприятием христианами языческих традиции и ритуалов, многие из которых сопровождались той или иной музыкой. Одновременно, игнорируя запрет, музыка начала проникать в христианские богослужения. Доказательством этому факту является «существование древних рукописей, содержащих раннехристианские гимны, написанные древнегреческими нотами» [15].

В скором времени «византийская музыкальная традиция стала дополнять и видоизменять древнегреческое культурное наследие, стремясь создать новую духовную музыку, отличную от языческой» [9, с. 107]. Именно эта музыкальная система, которая зародилась в Византии в период становления христианства, продолжала непрерывно развиваться на протяжении всей истории. В итоге «она превратилась в современную музыкальную традицию, которая повсеместно используется в православных и католических храмах на арабском Востоке» [9, с. 109].

Вернемся к важному моменту в истории, когда Сирия находилась под османской оккупацией. В этот период христианам запретили открыто проявлять религиозность и проводить свои обряды. Поэтому они практиковали их вне церкви, что привело к уменьшению популярности песнопения и церковных традиций среди православных сирийцев.

С приходом арабов под запрет попали некоторые сирийские песни, а вскоре стало обязательным использование арабского языка в песнопениях. Например, песня «Ярдали Ярдли Самра Каталтини» была очень популярна, но исполнялась на арабском языке, так как сирийский язык был запрещен.

Только в современную эпоху, начиная с 1950 года и до наших дней, молодежь начала возрождать сирийские мелодии и петь на языке Христа песни о любви, жизни, разлуке, боли и о разных страданиях человека в жизни. Появлялись и новые песни, которые потом распространились в диаспоре в Швеции, в Германии и в Сирии.

Музыка Византии - одна из самых мощных музыкальных систем, которая наполнена и способная воплощать различные человеческие эмоции. Об этом явлении свидетельствует «традиция изменять оригинальные песнопения, путём вставки мелодии в основу гимна, соответствуя «чувству и значениям речи»» [7].

Говоря о христианском влиянии на музыкальную 
культуру Сирии, нельзя не упомянуть о старейшем жанре христианской церковной музыки - псалмах Давида [17], которые были унаследованы христианами от храма Иерусалима. Псалмы были вплетены в христианский обряд и чаще всего исполнялись простыми людьми, которые посещали богослужения. Ритуалы Вечери Господней проводились вечером, таким образом представляя собой общую трапезу, перемежающуюся молитвами и гимнами. Некоторое время пение праздничных молитв и гимнов занимало тоже самое место в духовной жизни Церкви, что и Вечеря Господня. Однако вскоре группа монахов начала устанавливать правила и законы, регламентировавшие проведение богослужений.

В связи с этим, в монастырях, особенно в Сирии, образовалась новая музыкальная практика - пение Антонина, имитирующее ритуалы древних синагог. Стихи читались благоговейно до и после псалмов и других литургических песнопений, вскоре данная традиция перешла в церковь.

Популярность и распространение на территории Сирии получил и другой тип Византийской музыки - песнопения. Изначально данный тип пения напрямую относился к старейшему жанру христианской церковной музыки - псалмам. В последствие данные песнопения, такие как пение «Аллилуя» [16] были хорошо восприняты в раннехристианской церкви и стали частью обрядов.

Пение псалмов не могло полностью удовлетворить духовные потребности ранних христиан, поэтому достаточно скоро, уже во втором веке нашей эры, появляется новая форма христианской музыки - гимны. По своей сути гимны являются стихами, в которых автор, а также любой человек, который поёт эти гимны, пытается говорить с Богом, выражает свои чувства, благодарит, прославляет и просит о чем-то. Каждый гимн - это молитва к Богу. Некоторые гимны содержат учения о Вере, взятые из Библии и других источников.

Гимны получили особое распространение в период c V по седьмой век. В это время были сформированы основные принципы псалтирного искусства. Его развивали наиболее известные мелодисты и гимнографы, такие как: Роман Мелодист, Иоанн Дамаскин и Феодор.

Зарождение сирийской православной церковной музыкальной культуры можно проследить еще на заре христианства. Первые религиозные христианские композиции опирались как на фольклорную традицию, так и на предшествовавшие им обрядовые языческие песнопения, видоизмененные для нужд нового вероучения. Среди авторов, осуществивших этот труд можно отметить: Маравама, Марабола, Якоба Саруджи, Шимона АльФахари.
Так в Сирии, благодаря труду и авторитету Иоанна Дамаскина, получил распространение новый жанр гимнографии - канон, состоявший из девяти связанных друг с другом песнопении. Каждый гимн данного канона включает в себя вводный тропарь и еще несколько тропарей с разным текстом, исполняемые в одинаковом с ведущей мелодией ритме.

Иоанн Дамаскин обозначил характерные именно для сирийской церковной одноголосой музыки особенности, уделив много внимания её развитию [15]. Важной вехой в развитии православной духовной музыки в Сирии стала деятельность, начатая Ефремом Сириным [13, c. 130] в IV в. Не менее актуальной была «практика привлечения для церковных песнопений женского хора, что открыло для многих женщин возможность заниматься музыкой» [3, с. 209].

Спустя четыре столетия в христианской церковной музыке стали происходить изменения, так же как начали меняться традиции в самой церкви. B VI в. сирийским святым Ефремом Сириным была создана новая церковная музыкальная система, основанная на восьми мелодиях или ладах, распределенных на четыре оригинальных и четыре производных.

Обозначенная система легла в основу сирийской и византийской церковной музыки и на её основе возникли многие литургические произведения. В этом же веке были написаны стихи святого Романа аль-Хомси, в том числе стихотворение, восхваляющее Богородицу, которое до сих пор читается каждую пятницу Великого поста. Также Папа Григорий полагался на указанную систему при разработке системы гимнов, называемой амвросианское пение или григорианское пение, которое в последствии было принято Латинской церковью.

В данный момент в Византийской и Сирийской церквях, при проведении богослужений певчие используют особый метод византийской нотации - «новый метод» или «метод трёх учителей». Он был введен в 1814 г. тремя композиторами и теоретиками византийской музыки - Хрисанфом Мадитским, Григорием Протопсалтом и Хурмузием Хартофилаксом [22]. Этот метод используется и в настоящее время в православных церквях Константинопольского и Антиохийского патриархатов.

Отличительной чертой сирийской духовной музыки стало исполнение а cappella - пение без каких-либо музыкальных инструментов. Данная традиция напрямую перешла из Византийской церковной музыкальной системы. Пение христианских гимнов играло значительную роль в жизни верующего населения. Большое влияние на духовное развитие православных сирийцев в XIII веке имел Патриарх Иаков III Бартелли [20]. Он получил две почетные докторские степени: одну по теологии в Уни- 
верситете Льюиса и Кларка (Портленд - Ориген, 1960), а другую - за защиту диссертации гуманитарного направления в Университете Дрю (штат Нью-Джерси, 1971).

Патриарх приложил много усилий к развитию сирийской музыки. Он записал сирийские мелодии, содержащиеся в известной книге (Бет Кадзу). Эти очаровательные мелодии до сих пор захватывают чувства его слушателей, вызывая любовь и уважение к Патриарху Иакову III Бартелли. Известно также, что христиане пели свои псалмы не только в церквях, но также и в домах, на площадях и в дороге.

Помимо формальной литургической музыки, сирийские православные общины также разработали современную духовную музыку, которую часто можно услышать на общественных собраниях.

Богатое музыкальное наследие Сирийской Православной Церкви сегодня можно ощутить в любом сирийском православном ритуальном богослужении, будь то евхаристическая литургия или другие таинства, такие как крещение, венчание, ежедневные службы или праздники.

Подводя итоги исследования, отметим, что за годы своего развития, сирийская музыкальная культура многое переняла от Византии и христианской традиции. В этой связи важно рассмотреть отдельно византийское влияние и влияние христианства на культуру Сирии, в

\section{частности на музыкальную культуру.}

Музыка в византийской христианской церкви - это, в первую очередь, молитва, поэтому в ней не использовались музыкальные инструменты. Считалось, что только человеческий голос в своей естественной форме достоин прославлять Создателя, так как голос наиболее ясно и точно передаёт искренность эмоций и откровенность чувств, и не отвлекает людские души, как это делают звуки музыкальных инструментов.

Одним из важнейших элементов византийской музыкальной культуры, повлиявших на сирийскую музыку, является система музыкальной нотации - невменная система. Она состоит из знаков, которые обозначают ход голоса, ритм. Постепенно данная система развивалась и трансформировалась, однако её сущность осталась прежней.

Ранние христианские авторы Сирии предпочитали поэзию как метод богословского выражения, используя образы и символы как основу всего человеческого опыта. Они создавали поэтические произведения, гимны, которые могли бы донести до обывателей основы вероучении и христианской культуры. Во многом благодаря этим сподвижникам, пение гимнов и гимнография получила особое распространение в Антиохийской церкви (Сирии) и оказало значимое влияние на культуру всего общества.

\section{ЛИТЕРАТУРА}

1. Ахмед Дауд. Древняя история сирийской цивилизации - Дамаск: Дар Сафри, 2004. - 703 с.

2. Ахмед Эрхим Хбо. Вехи семитской цивилизации и их история в Сирии и Месопотамии. Дар Аль-Калам Аль-Араби - Дар Аль-Рифаи: Сирия - Алеппо, 2003. -235 c. - C. 62 .

3. Барсом. И.А. Рассеянный жемчуг: история сирийской литературы и наук, 1920. - 611 с.

4. Борзова Е.П. История мировой культуры: учеб. пособие для вузов искусств и культуры - СПб.: Лань, 2007. - 672 с.

5. Борзова Е.П. Культура и политические системы стран Востока: учеб. пособие - СПб: «СПбКО», - 2008. - 550 с.

6. Борзова Е.П. Сравнительная культурология. В 2 т. - СПб.: «СПбКО», 2013. - 524 с.

7. Джозеф Язбек. 06 истории византийской музыки и о том, как она отделилась от сирийской музыки [Электронный ресурс]. Режим доступа: https://www.youtube.com/watch?v=PuHsPkWxXAs (дата обращения - 01 мая 2021 года)

8. Донцов В.Е. Исторические традиции российско-сирийских отношений. Сб. «Ближний Восток и современность». Вып. 28. - М. - ИБВ, 2006. - 266 с.

9. Книга музыки и пения от начала создания до наших дней. - СПб.: Arab Press Agency, 2019. - 173 с. - С. 107.

10. Колокола Востока | Композитор Нури Искандар (أجر اس المشرق | المؤلف الموسيقي نوري اسكندر) [Электронный ресурс]. Режим доступа: https://www.youtube.com/watch?v=GewGP8T9E (дата обращения - 16 мая 2021 года)

11. Марио Багос. От древнего Ближнего Востока до христианской Византии: короли, символы и города. Издательство Кембриджских ученых, 2021. - 302 с.

12. Мохаммад Ибрахим Назир. Военно-политические отношения Российской федерации и Сирийской Арабской Республики в 2000-2012 гг:: историческое исследование. - [Электронный ресурс]. - Режим доступа: http://vagsh.mil.ru/upload/site17/document_file/W5QJYpiN8J.pdf (дата обращения - 04 мая 2021 года)

13. Пигулевская Н.В. Культура Сирийцев в средние века. Главная редакция восточной литературы. - Москва: «Наука». 1979. - 249 С. - С. 130.

14. Преподобный Герасимос Кутсурас. Православная христианская церковная музыка - Византийская музыка [Электронный ресурс]. - Режим доступа: https://www.greekorthodox.org.au/?page_id=3372 (дата обращения - 28 апреля 2021 года)

15. Преподобный Иоанн Дамаскин, Точное Изложение Православной Веры. Издательство Сретенского монастыря. Москва, 2003. - 162 с.

16. Признайся Господу, Он добр Аллилуиа. Византийские хоровые гимны [Электронный ресурс]. - 


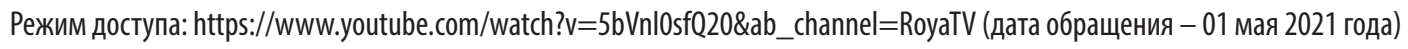

17. Псалмы Давида: Поэтические книги Ветхого Завета, Университет короля Суд 223. - 60 с.

18. Рапацкая Л.А., Харфуш Р. Культурологическим подход к периодизации развития сирийской музыкальной культуры как научный инструментарий её освоения будущими музыкантами-педагогами в России // Музыкальное искусство и образование. 2019. №3. URL: https://cyberleninka.ru/article/n/ kulturologicheskim-podhod-k-periodizatsii-razvitiya-siriyskoy-muzykalnoy-kultury-kak-nauchnyy-instrumentariy-eyo-osvoeniya-buduschimi (дата обращения: 11.04.2021).

19. Сирийское пение от Шумера до Залаина ( الغناء السرياني من سومر إلى زالين ) [Электронный ресурс]. Режим доступа: https://kassioun.org/more-categories/art-and-culture/item/50216-23965 (дата обращения - 03 мая 2021 года)

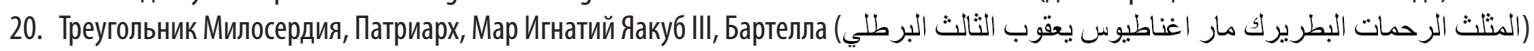
[Электронный ресурс]. - Режим доступа: https://www.ishtartv.com/viewarticle,42771.html (дата обращения - 17 мая 2021 года)

21. Фрэзер Дж. Дж. Фольклор в Ветхом Завете. - М.: АСТ; Ермак, 2003. - 542 с.

22. Byzantine notation versus Western Notation - St. Anthony's Greek Orthodox Monastery [Электронный ресурс]. Режим доступа: http://www.stanthonysmonastery.org/music/NotationB.pdf (дата обращения - 17 апреля 2021).

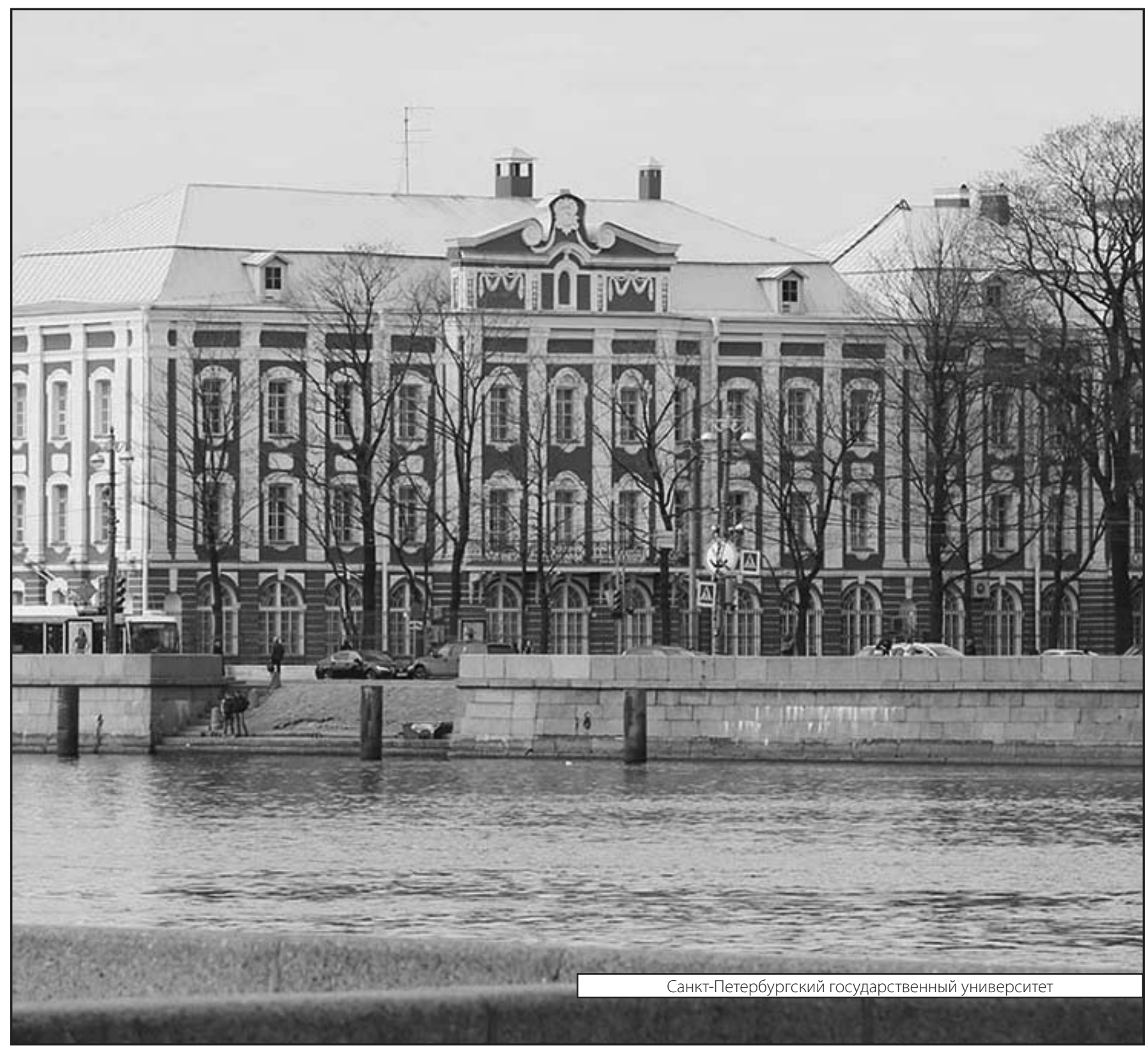

